\title{
A Lazy User Perspective to the Voluntary Adoption of Electronic Personal Health Records (PHRs)
}

\author{
K. Niki Kunene \\ Eastern Connecticut State University \\ niki.kunene@gmail.com
}

\author{
MameFatou Diop \\ Eastern Connecticut State University \\ diopm@my.easternct.edu
}

\begin{abstract}
Personal Health Records (PHRs) have been imbued with the potential to improve health outcomes for individual healthcare consumers, providers, and the broader healthcare system. With Meaningful Use Stage 2 now mandating the implementation of tethered PHRs, tethered to provider electronic health records (patient portals), will healthcare consumers voluntarily use PHRs and contribute to safety, quality, efficiency and reduced health disparities through engagement? Or will PHR use remain low? In this qualitative study, using grounded theory, we asked users how they currently managed their personal health information (PHI) and why. Using the lazy user model, we found that letting physicians manage healthcare consumers PHI is the least effortbased solution and thus the predominant and preferred solution. Providers as guardians of patient PHI suggests the low use rates may persist yet. We should do more to make these technologies usable and accessible to those with irregular contact with a primary care physician.
\end{abstract}

\section{Introduction}

Personal health records (PHRs), unlike electronic health records (EHRs), are intended to be controlled by the consumer. Personal health records were conceived to give the individual consumer the ability to manage, track, share and participate in his/her own healthcare [1-4]. PHRs are part of the need to engage patients in their own care.

Whereas, the EHR is the domain of the healthcare provider. A PHR may however, be directly linked to a provider's EHR as a tethered PHR. On the other end of the spectrum, a PHR may be untethered to any specific provider allowing the patient to populate the PHR, fully or partially, with information from multiple provider EHRs (doctors, pharmacies and labs) as well as information entered by the healthcare consumer herself $[1,2]$. Some PHRs are even tied to the patient's medical librarians, where a librarian is given access to share pertinent health information. Tethered PHRs are by definition provided and maintained by healthcare organizations such as hospitals, doctor groups, health insurance companies, employers. Untethered PHRs are provided by private vendors who may or may not charge a use fee [1].

The multiple benefits to using PHRs have been articulated by both researchers and policymakers. Following the HITECH Act of 2009, five objectives of the Meaningful Use (MU) of electronic healthcare records were articulated in realization of the Act. Three of these objectives (therein numbered 2-4) are especially pertinent to PHR benefits: (a) engaging patients and families in their health; (b) improving care coordination, (c) improving population and public health. (The first objective calls for improving quality, safety, efficiency, and reducing health disparities (Stage 3). Objective five calls for ensuring adequate privacy and security protection for personal health information). Wynia and Dunn [5] also identified the expansion of health education opportunities and strengthening disease prevention as purported PHR benefits. Another primary benefit of PHRs is greater patient access to a wide and customizable array of credible health information, data, and knowledge [3]. Mobile personal health records (mPHRs) can help in case of emergencies when a patient sees a new provider, or where the patient's primary EHR is not accessible, or interoperable with the new provider's systems [6]. One design researcher has suggested the PHR as a landing solution for overcoming the lack of interoperability between providers' EHRs that serve the same patient.

PHRs have been around for some time, and with beliefs in their various potential benefits holding firmly among policymakers and researchers, efforts to encourage their adoption are well under way. As a result, patient access to PHR has been growing rapidly. Studeny and Coustasse [7] reported that over 70 million consumers had access to tethered PHRs in 
the United States. And, (free) access to untethered PHRs, like Microsoft's HealthVault, have existed for over a decade. Legally, the implementation of Stage 2 of Meaningful Use requires providers to use technical capabilities offered by PHRs, for example: communicate electronically with patients, provide patients the ability to view, download and transmit their electronic health information within days. Providers are responding by creating patient portals (tethered PHRs) where EHR health information can be viewed but not modified by the patient. Some providers may even show the patient how to log into the portal during patient visits. And yet patient use of PHRs remains low, despite policy efforts to promote their use [4, 5].

Researchers and policy experts continue to deliberate over whether PHRs will ever gain the necessary adoption rates to make the systems effective [4, 5, 7]. Several barriers to adoption have been identified. These barriers impact the decision to start using a PHR, the adoption process and the continued use of PHRs [8]. Patient-centered barriers to adoption, from the literature, include concerns for information privacy [9-11], patient awareness, and/or interest [12]; patients' ability to understand medical records [4]. From a provider-centered perspective, the lack of provider reimbursement for time spent in portal communication [7], and the response time required of providers [4]. Furthermore, from a social and economic perspective, digital divide [13], socioeconomic status, race, education are also important factors in the adoption and diffusion of PHRs [8].

While much quantitative research has been done in this area, there are few qualitative and recent studies on the adoption of PHRs; fewer still that have generalized to theory. The purpose of our research project is to get an in-depth qualitative understanding of (1) how individual healthcare users in New England, USA currently manage their personal health information, (2) whether they have adopted an electronic personal health record (PHR) and the factors that influenced their voluntary adoption or non-adoption of a PHR. The study uses grounded theory whose data collection strategy is semi-structured interviews. Two generative open- ended questions form the basis of the interview between investigator and research participant. This paper describes the emergence of lazy user theory [14] in the selective coding process of grounded theory that reassembles and integrates categories or themes to theory. In [15] we reported on the initial thematic categories emerging from the analysis.

The rest of the paper is organized in the following: Sections: 2. Background literature where we summarize predominant research themes in the literature, then briefly describe specific exemplars; and reviews theories and models of technology adoption. 3. Presents our research questions and methodology. 4. Discussion and 5. Conclusion.

\section{Background literature}

In this section, we discuss relevant literature related to the management of personal health information, and theories of technology adoption and diffusion.

\subsection{The management of electronic personal health information (ePHI)}

The drive to implementing electronic healthcare records is, in general, motivated by the potential benefits to consumers, population health, healthcare providers and the healthcare system overall through cost savings and reductions. For PHRs, patient engagement in their own care and health [16] is believed to be at the core of additionally accruing benefits.

Prior research on PHRs has sought to understand consumer perspectives towards personal health records within defined communities, in light of the low adoption rates. A majority of these studies are quantitative studies using surveys for data collection, a few are structured reviews of the literature, fewer still are qualitative studies or experimental trials. Nevertheless, common findings or themes are frequently found in the literature. Privacy and security concerns [2, 10,11, 17-19] are a frequently stated barrier to adoption. Differences characterized by socio-economic divides, e.g. the digital, racial/ethnic and income divide $[13,20]$ can divide groups into adopters and non-adopters. The intersection age and comfort with technology also has an impact amongst middle-aged and older patients [21]. Further, the interoperability problem, a technical challenge that affects both for both PHRs and EHRs [22] may be a barrier to adoption, particularly with multiple non-interoperable tethered PHRs where patients are granted access to multiple patient portals. Last but not least, physicians can serve as an adoption influencer, therefore the rate of adoption of electronic health records (EHRs) and the variances in physician willingness to use technology in managing patient care influences patient adoption of PHRs [23]. Yet multiple studies also show many patients believe using PHRs can help them better manage their health, or improve care quality $[17,22]$, and that this belief is also prevalent in groups with low income levels, and minority racial/ethnic groups [19, 24].

For example, Abramson et al. [17] conducted a cross-sectional, pooled survey study from four communities. They found a majority of consumers said they would use a PHR; that consumers believed that 
PHRs may improve the quality of their care, and improve the security of their personal health information. Abramson et al. [17] also found that Internet use was significantly associated with, at least monthly, potential PHR use. To reduce the gap between actual and potential, usage Abramson et al. [17] conclude, PHRs must offer high security and privacy standards and be perceived to improve the quality of care.

In a qualitative study, Young et al. [25] examine the barriers to PHR adoption among older adults in homebased care. They interviewed adults in the age range of 46-72 years and found barriers to adoption were characterized by four themes: (1) privacy and security concerns; (2) general technological discomfort which made participants view the idea of electronically communicating with healthcare providers of "dubious value" [25]; (3) lack of relative advantage -where the use of PHRs or their equivalent were not perceived to be more advantageous to paper; (4) an undesirable user representation -where participants imagined a user of PHR as someone infirm, or with a chronic condition, or someone irresponsible requiring constant reminders, i.e. someone unlike themselves.

Mitchell and Begoray [26] also show that patients with serious and/or long-term illnesses can benefit the most from these systems [26]. Yamin et al. [13] found patients with comorbidity, i.e. those with two simultaneous chronic conditions, were more likely to use a (tethered) PHR system. Yamin et al. compared the use and non-use of a tethered PHR. Wagner et al. [27], in a cluster-randomized effectiveness trial with PHR and non-PHR groups, investigated the impact on several measured outcomes of PHR use among hypertensive patients. They found no PHR impact on blood pressure (BP) was observed. They also found that few patients with access to a PHR "actually used one with any frequency". They conclude, merely providing a PHR had no impact on the defined outcomes: BP, empowerment, satisfaction with care, or use of healthcare services without additional education, or clinical interventions designed to increase PHR use [27].

Some studies have looked at the barriers to adoption from a physician perspective. Vydra et al. [4] found there was mismatch of physician time spent on portals and a lack of compensation for that time that was a diffusion barrier for PHRs. In a structured review of existing literature, . Lester et al. [7] also found physician concern for patient understanding of medical records, legal liability, as well as the response time required of physicians to be burdensome to physicians.

Tang et al. [3] suggested that there are two main mechanisms for understanding and unravelling the barriers to PHR adoption, namely, education and research. They argued that we "do not know enough about health care consumers' need for, and potential use of PHRs" [3]. Some Human-Computer Interaction (HCI) researchers have postulated that the adoption of PHRs would be subject to "captology" [28]. Captology is a theoretical framework established in HCI research. The framework holds computers as "persuasive technologies" that can motivate, influence, and persuade users toward the adoption of target behaviors [28] or engineered behavior[29].

\subsection{Theories of technology adoption and diffusion}

Several theoretical models study the adoption, diffusion and acceptance of technology and technical devices, these include: the theory of reasoned action [30], theory of planned behavior [31], technology acceptance model $[32,33]$, unified theory of acceptance and use of technology (UTAUT), technology task fit [34, 35], Roger's diffusion of innovations [36], cognitive fit theory $[37,38]$ and the Lazy User Model [14]. The most influential of these is the Technology Acceptance Model (TAM) [32, 33] and its variants.

The origins of TAM are traced back to the theory of reasoned action (TRA) [30] and the theory of planned behavior [31]. TRA posits that behavior is dependent on behavioral intentions; that behavioral intention is dependent on the attitude toward the behavior and subjective norms. The theory of planned behavior [31], an extension of the theory of reasoned action [39] adds the construct, perceived behavioral control as an exogenous variable that has both a direct effect on behavior as well as an indirect effect through intensions. The indirect effect through intentions signifies the motivational effect of control. That is, when people believe they have no control over a behavior, be it through lack of resources, then the intention to perform the behavior may be low even where attitudes are favorable [40]. Thus, perceived behavioral control refers to the perceived ease of adopting the behavior.

Foundational to TAM are the two constructs proposed by Davis [32]: perceived usefulness and perceived ease of use. These two constructs, in Rogers' diffusion of innovations [36], are among the set of perceived characteristics of innovations through which beliefs about IT usage are captured [41]. In the unified theory of acceptance and use of technology (UTAUT), an extension of TAM, Venkatesh et al. [42] articulate four key constructs as having a direct effect on intention, namely performance expectancy, social influence, effort expectancy and facilitating conditions.

The Lazy User Model [14] is grounded in the idea of employing the least effort or least energy to fulfill a need. The concept exists in physics, linguistics, 
informatics or information seeking [14]. The concept of a lazy user in research has been used in information retrieval, and finance with "lazy banking" [14]. Tétard and Collan [14] proposed the lazy user model as a technology adoption in information systems. The model posits, a user will most often choose the solution that will fulfill their (information) needs with the least effort (lazy user behavior) [14]: "The lazy user theory of solution selection tries to explain how an individual (user) makes her selection of solution to fulfill a need (user need) from a set of possible solutions (that fulfill the need). The set of possible solutions is a subset of universal solutions that is constrained (limited) by the user state (circumstances)" [14].

Graphically, the model is shown below in Figure 1.

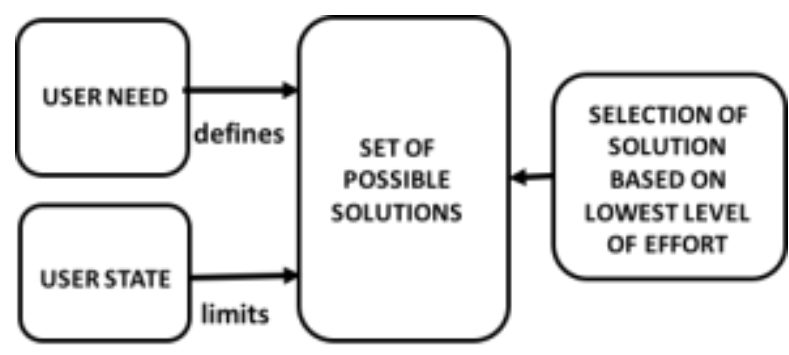

Figure 1. The lazy user model (adapted from Tétard \& Collan) [14]

The model is fully described by Tétard and Collan [14] who also point out the TRA has limitations when a user must make a choice in face of multiple options [14, 43].

\section{Research questions and methodology}

The study is a qualitative study using grounded theory $[44,45]$ as research method, appropriate for the development of theory "grounded in data systematically gathered and analyzed" where theory evolves. Our data collection strategy is semi-structured interviews; study participants do not merely serve as a conduit of information but also participate in meaning-making [46].

Two generative questions, asked of our study participants, formed the basis of the inquiry in semistructured interviews:

i. How are you currently managing all your healthcare data (prescription data; medical bills, test and lab results, historical medical data)?

ii. Do you use a personal health record (PHR)? What considerations incent or would incent you to use a personal health record? What considerations discourage or would discourage you to use a personal health record?

For analysis, three types of coding are used as part of constant comparative analysis, allowing for the iterations of the interplay between data collection and analysis, i.e. open coding, axial coding and selective coding. Open coding is used for preliminary segmenting, axial coding for theme-ing (generating the "codes") and selective coding for analyzing themes into cohered understandings or theory.

\subsection{Data gathering}

The research was carried out in New England, USA. Data was collected in three periods. The first round of interviews was conducted in December of 2014; the second and third rounds in the Spring and Fall of 2015; and fourth in the Spring of 2016, and Summer 2017*. Subjects ranged between 21-65 years in age and nearly evenly divided with respect to gender. The study was approved by our institutional IRB. The only exclusion criterion used was, subjects had to be 21 years older. An average of 28 subjects are interviewed in each of the first three rounds each; only $2 *$ subjects are interviewed in the final round. Each interview lasted between 20-60 minutes and was recorded for transcription. The last round of data collection was added as result of the iterative constant comparative analysis to target intensive users of PHRs who do not suffer a chronic disease.

\subsection{Data analysis}

The objective of using grounded theory is to tell a cohering story by unearthing a central theme or category from the multiple emergent themes. A central category has analytic power: "the ability to pull other categories together to form an explanatory whole" [47] while accounting for variation within categories [47].

Two researchers code each of interview scripts. For open-coding the initial categories were age, gender, education, prior knowledge of PHRs, privacy attitudes, security attitudes, state of current health. The emerging themes (axial coding) from abovementioned categories are partially shown below in Tables 2 and 3. With selective coding, where we integrate and refine categories to a more abstract concept or theory, we have kept an open mind with respect to mapping back to existing theory as a central concept. 


\section{Results and discussion}

A total 85 subjects have been interviewed over a period of nearly two years. A majority of our respondents considered themselves to be in good health, only five of our 85 subjects explicitly referred to a chronic health condition that required ongoing treatment: anxiety, Type I and II diabetes, thyroid disease, and severe sinusitis. Age distribution is: 21-35 [47], 36-50 [40], 51-65 [13\%]. The gender split was $54 \%$ female- $46 \%$ male. Unprompted only $35 \%$ knew what a PHR or patient portal was and about the same number reported being aware of having access to a PHR. Nearly all our respondents reported having a primary care physicians who had adopted certified EHR technology (CEHRT); only one respondent reported a paper-based primary care physician, there remainder were unsure.

Table 1. About our res pondents

\begin{tabular}{|c|c|}
\hline $\begin{array}{l}\text { Three rounds of } \\
\text { interviews }\end{array}$ & $\begin{array}{l}\text { Spring 2015, Fall 2015, } \\
\text { Spring 2016, Summer } \\
2017\end{array}$ \\
\hline $\begin{array}{l}\text { Number of } \\
\text { subjects } \\
\text { interviewed }\end{array}$ & $\begin{array}{l}85 \text { in total (not all } \\
\text { scripts have been coded } \\
\text { yet) }\end{array}$ \\
\hline $\begin{array}{l}\text { Male:Female } \\
\text { Ratio }\end{array}$ & $46: 54 \%$ \\
\hline $\begin{array}{l}\text { Self-reported } \\
\text { relative wellness }\end{array}$ & $\begin{array}{l}\text { Majority report being } \\
\text { healthy } \\
\mathbf{5} \text { indicated chronic } \\
\text { conditions }\end{array}$ \\
\hline $\begin{array}{l}\text { Knowledge of a } \\
\text { PHR }\end{array}$ & $\begin{array}{l}35 \% \text { reported knowing } \\
\text { what a PHR was } \\
20 \% \text { thought they knew } \\
\text { what it was, once it was } \\
\text { described to them. }\end{array}$ \\
\hline Access to a PHR & $\begin{array}{l}35 \% \text { have access to } \\
\text { PHR, or report being } \\
\text { aware that they have } \\
\text { access to a tethered } \\
\text { PHR } \\
\text { Approx. } 1 \% \text { of total } \\
\text { subjects have adopted a } \\
\text { PHR }\end{array}$ \\
\hline
\end{tabular}

\begin{tabular}{|l|l|}
\hline Primary & Nearly 93\% Report \\
Physicians Using & Yes. Others could not \\
CEHRT & $\begin{array}{l}\text { say definitively, i.e. had } \\
\text { not noticed. }\end{array}$ \\
\hline
\end{tabular}

\subsection{The lazy user}

In this manuscript we focus on the first generative question and draw on the Lazy User Theory [14] as an organizing and explanatory theoretical abstraction for our grounded theory findings. In a prior manuscript [15], we reflected on emergent themes from both generative questions. The lazy user theory is an adoption model that departs from the premise, a user will most often choose the solution that will fulfill their (information) needs with the least effort (lazy user behavior) [14]. Choice presupposes a options or an option set for fulfilling user need.

In our study, the model serves as an analytical abstract for selective coding [47]. Here we focus on the first question we asked of our respondents, "How are you currently managing all your healthcare data (prescription data; medical bills, test and lab results, historical medical data?" In other words, the question seeks to explore the array of possibilities universally for managing personal health information (PHI), as well as the solution respondents have chosen.

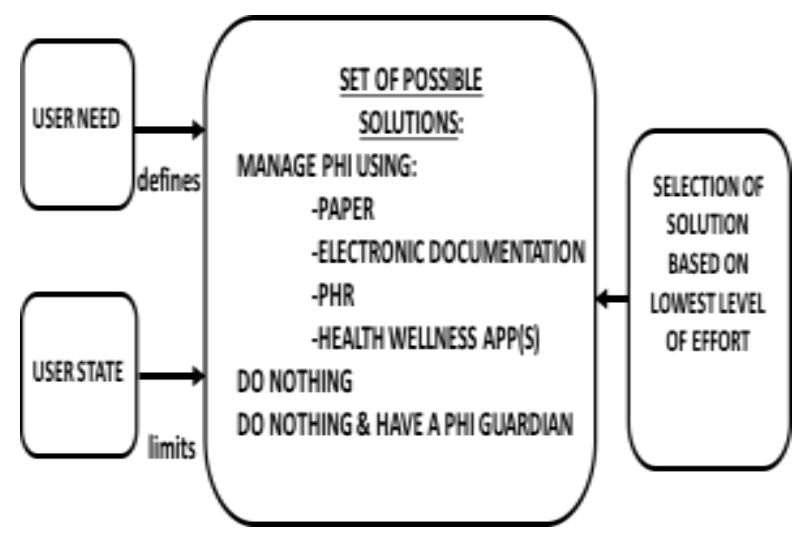

Figure 2. Our lazy user analys is model for PHR adoption

In this study's context, the user need is managing personal health information (PHI) to support one's quality of health and quality of care.

User Need: Managing personal health information.

The user state, in this context, is more multilayered and complex (than the business cases) discussed in [14]. The user state is a description of the 
user and their context at the time of need. The context for healthcare consumers is: relative state of health, this includes the presence or absence of chronic diseases particularly, but it also encompasses relative concern for health wellness which in our case is reflected through reported diet and exercise behaviors and/or concerns. It also includes the healthcare consumer's age. Younger and middle aged respondents perceived themselves as having minimal need for being engaged in their health through the managing and awareness of their electronic personal health information (PHI).

User State: Relative health and wellness; the presence or absence of chronic disease; diet/exercise behaviors and concerns; age.

The set of possible solutions for managing personal health information for healthcare consumers ranges from traditional paper solutions where users keep some file or folder related to their personal health information (some of our older respondents do). A second option is, maintaining electronic records of some kind, some of the respondents reported "keeping files on the computer." A third and fourth option is using a personal health record, and here one can distinguish between PHRs tethered to provider EHRs and untethered PHRs like Microsoft's HealthVault. Each option comes with its own set of challenges and conveniences. For instance, tethered PHRs open the consumer to the very real possibility of having multiple PHRs each associated with one of various healthcare providers (i.e. until the interoperability issue is settled). An untethered PHR comes with its own set of constraints: learning investment; privacy and security challenges, real or perceived. A fifth option is a partial solution to managing PHI, but does reflect a degree of patient engagement, i.e. the use of heath wellness mobile apps and wearables that invariably store the information electronically, and frequently on ubiquitous cloud storage. There are learning investment constraints in general; these may be perceived as transferable learning investments [14]. Many of our female respondents in particular used at least one health wellness app or wearable. The (adoption) effort to get a more comprehensive personal health information picture is constrained by the perception that too many apps would be required. The sixth option is to simply do nothing about managing one's personal health information. Last but not least, the seventh option is to do nothing personally and simultaneously have a guardian or agent manage your personal health information for you.
Possible Solutions: [paper management; electronic documentation; tethered PHR; untethered PHR; health and wellness apps and wearables; Do nothing; Do nothing and have a guardian or agent acting on your behalf] Table 2. Organizing catego ries for
Question 1

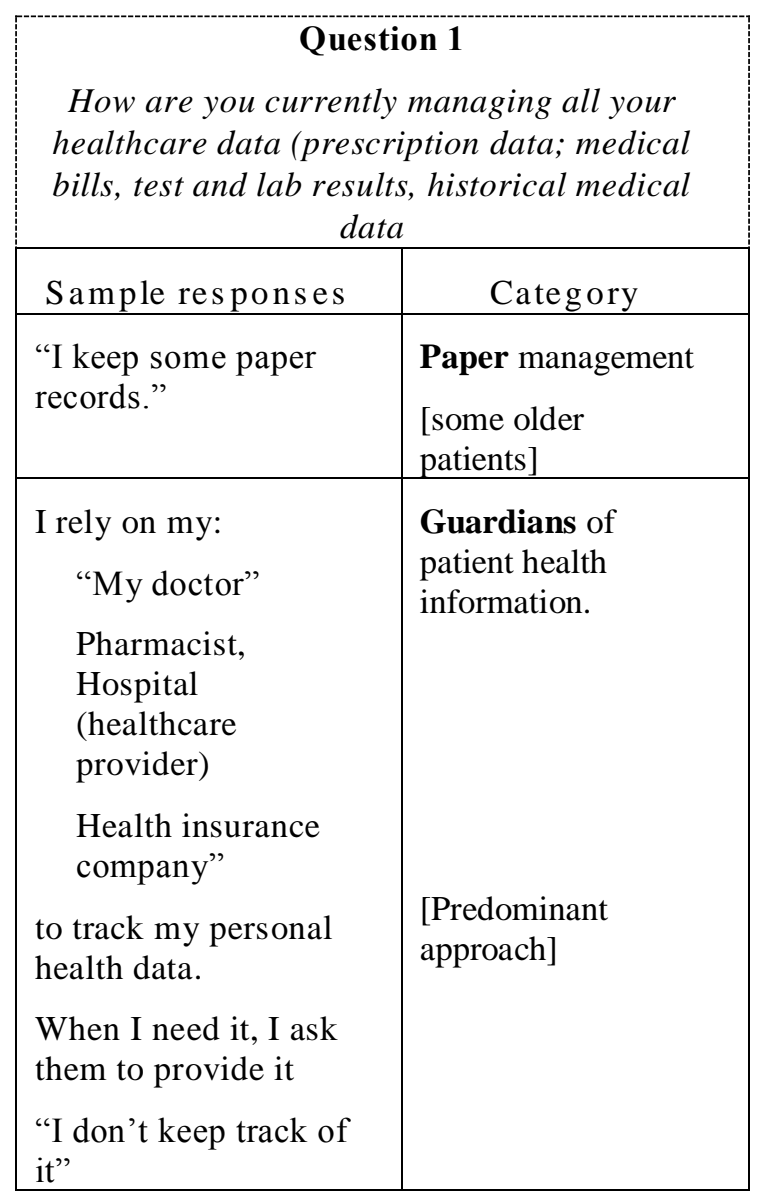

In our initial findings [15], we reported that the predominant approach taken by our respondents was to let their healthcare providers, physicians, pharmacists manage their personal health information for them, as well as the health insurance companies. Some of the reasons, included avoiding the hassle of a scarcely required event, not having the time, being too busy, or being lazy (see Table 3 below): 
Table 3. Reas ons given for not adopting a PHR

\begin{tabular}{|l|l|}
\hline \multicolumn{1}{|c|}{$\begin{array}{c}\text { Sample } \\
\text { Responses }\end{array}$} & \multicolumn{1}{c|}{ Category } \\
\hline $\begin{array}{l}\text { "I don't visit the doctor } \\
\text { nearly often enough for } \\
\text { the hassle, perhaps } \\
\text { when I'm older" }\end{array}$ & I'm healthy \\
\hline $\begin{array}{l}\text { "Honestly I } \\
\text { don't have } \\
\text { time for that" }\end{array}$ & $\begin{array}{l}\text { Perceived } \\
\text { Required } \\
\text { Time and } \\
\text { Effort }\end{array}$ \\
\hline $\begin{array}{l}\text { "I'm lazy. } \\
\text { I wouldn't update it" }\end{array}$ & $\begin{array}{l}\text { Perceived } \\
\text { Required } \\
\text { Time and } \\
\text { Effort }\end{array}$ \\
\hline
\end{tabular}

We found that, self-perceptions of relative health, together with the perceived effort and time required to upkeep a personal health record discourage healthcare consumers from adopting personal health records [15]. The factors captured in Table 3 (above) came up repeatedly amongst our (self-described) healthy respondents. Notably, in this context, where the user need is continuous rather than episodic, or event-based, the lazy user appears to also be the busy user. This does not suggest users did not have other concerns about PHRs, e.g. privacy [15], but that other concerns were not cited as the reason for not adopting a PHR in the same as the factors reflected in Table 3 above. Furthermore, consistent with prior literature, our respondents believe using a PHR would benefit their health [15].

\subsection{Discussion}

As we iterate to selective coding to formulate a coherent explanation of our findings, the Lazy User theory has been a useful analytical tool for explaining adoption behavior. Altogether, almost half our respondents knew or had knowledge of what a PHR was once it was described to them. Many knew it as a (tethered) patient portal, and a majority thought using a PHR would positively impact their health. The lazy user theory helps explain why they are nevertheless not likely to be persuaded to use it.

Although our study has not yet fully complete, it is clear that given the set of options healthcare consumers have: do all the perceived work of managing your health information, or have an agent or guardian do it for you, the choice decision for the user is easy. This appears particularly true for "healthy" users. Although, one of our respondents had a chronic illness (thyroid) and had been instructed by their primary care physician to use a PHR to keep track of certain metrics, the respondent said they didn't do it and were not planning on doing so anytime soon, perhaps "if it got really bad," But, they said, they "kept up with all their scheduled doctor's appointments where all this information is recorded, anyway." The respondent had a sense that constantly recording this data was a hassle or something that their time did not allow for, and seemingly they didn't think they were sufficiently unwell to do so. Further, they felt the physician was already doing it for them. The idea that the provider was already managing this information was not unique to the participant with a thyroid condition. A large majority of respondents answered, the first question with "I don't, my doctor does", others with or "I let my doctor do it". "If I need it, I call the doctor." This is a very different choice to my health information goes unmanaged.

The cohering of these first level constructs $[48,49]$ (the respondents' own understandings) and the second level construct of the lazy user theory has greater explanatory power in our context than competing theories. Many researchers, including ourselves [39], have for example advocated for more education of users about PHRs. However, with the implementation of Meaningful Use Stage 2, persuasion rather than knowledge (Diffusion of Innovations [36]) is going to be the sticking point. Will the actual use of PHRs increase just because the primary care physician's assistants show the patient how to log into the patient portal? Our findings suggest not. Certainly, not for the majority selfdescribed as healthy, young and middle-aged. This may be of concern to health-care providers and policymakers, particularly with respect to stealthy diseases such as high blood pressure that require regular monitoring and patient engagement.

It may also concern anyone concerned about the socioeconomic disparities that reduce access to primary care physicians. If primary-care physicians and careproviders are de-facto guardians of our personal health information, and our engagement in our health is directly mediated through them, then those with irregular access to these guardians are most disadvantaged. In fact, it would serve the broader healthcare system if the adoption of PHRs was highest among those with irregular access to primary care physicians. Can PHR applications, particularly untethered PHRs, be designed for captology and what would that look like?

The two generative questions we started the study with were conceived so the first question sheds light on how users manage their personal health information, and the second to elicit reasons for the presence or absence behaviors and choices in this regard. Although 
our task is not quite complete, Iterating to a theoretical abstract in grounded theory requires us to evaluate all the categories arising and open coding and axial coding and account for variations within categories using the core category (i.e. The Lazy User Theory), e.g. security, privacy concerns and "if you pay me" financial incentives [15]. Then we must refine the theory. We have already observed that in our context, the lazy user may also be the busy user. It is however normal for researchers using grounded theory's iterative constant comparative analysis to come upon the so-called core category, i.e. theoretical abstract, prior to completing the analysis as they iterate to completion.

Why we ruled out competing theories: First, because we are using grounded theory for sensemaking, it is where the data, the participants own words have taken us. Second, our participants have multiple options, even among PHRs, there is no specified standard (technical, legal, or other) for PHRs. In the presence of choice, models grounded in the theory of reasoned action have limitations $[14,43]$. Third, our data suggests, while they have a choice of a PHI guardian, healthy consumers will choose making use of the guardian rather than be custodians of their own data. Consideration of the would-be tool barely makes the surface. Other theories would require a consideration and perceptions of the innovation itself, our participants did not, bar generalized perceptions of technologies they use.

\section{Conclusion}

There are not many qualitative and recent studies on the adoption of PHRs. Most of the studies are quantitative and literature studies. The contribution of study is to bring an in-depth, qualitative look whose sense-making comes from marrying study participants' understandings of their behavior (first level constructs) with researcher second level constructs using grounded theory. This has led us to the conclusion that the Lazy User Theory, based on the principle of least effort, provides a reasonable explanation why consumers who perceive themselves as healthy, notwithstanding all the effort invested in getting them to adopt and use PHRs, will choose to let their healthcare providers manage their personal health information when the option exists. Stated simply, they can't be bothered to do it themselves, they are too busy or too lazy.

Relying on healthcare providers as guardians of our PHI may have particularly adverse implications for people who have irregular access to healthcare. We should do more to make these technologies usable and accessible to those with irregular contact with a primary care physician. For information systems research, usability studies of untethered and free PHRs as well as patient portals tethered to provider EHRs seem warranted, for researchers to better understand what about the artifact, in-use, drives users to use or not use PHRs. Perhaps then, we may learn what captology or persuasion may look like for the lazy user.

\section{References}

[1] Jones, D. A., et al., "Characteristics of personal health records: Findings of the medical library association/national library of medicine joint electronic personal health record task force". Journal of the Medical Library Association: JMLA, 2010. 98(3): pp. 243.

[2] Kaelber, D. C., et al., "A research agenda for personal health records (PHRs)". Journal of the American Medical Informatics Association, 2008. 15(6): pp. 729-736.

[3] Tang, P. C., et al., "Personal health records: definitions, benefits, and strategies for overcoming barriers to adoption". Journal of the American Medical Informatics Association, 2006. 13(2): pp. 121-126.

[4] Vydra, T. P., et al., "Diffusion and use of tethered personal health records in primary care". Perspectives in Health Information Management, 2015. 12(Spring).

[5] Wynia, M. and K. Dunn, "Dreams and nightmares: practical and ethical issues for patients and physicians using personal health records". The Journal of Law, Medicine \& Ethics, 2010. 38(1): pp. 64-73.

[6] Bouri, N. and S. Ravi, "Going mobile: how mobile personal health records can improve health care during emergencies". JMIR mHealth and uHealth, 2014. 2(1): pp. e8.

[7] Lester, M., et al., "Personal Health Records: Beneficial or Burdensome for Patients and Healthcare Providers?". Perspectives in Health Information Management, 2016. 13(Spring).

[8] Showell, C., "Barriers to the use of personal health records by patients: a structured review". PeerJ, 2017. 5: pp. e3268.

[9] Lehnbom, E., H. Douglas, and M. Makeham, "Positive beliefs and privacy concerns shape the future for the Personally Controlled Electronic Health Record". Internal Medicine Journal, 2016. 46(1): pp. 108-111.

[10] Señor, I. C., J. L. Fernández-Alemán, and A. Toval, "Are personal health records safe? A review of free web-accessible personal health record privacy policies". Journal of Medical Internet Research, 2012. 14(4): pp. e114.

[11] Carrión, I., J. L. F. Alemán, and A. Toval. "Assessing the HIPAA standard in practice: PHR privacy policies". in Engineering in Medicine and Biology Society, EMBC, 2011 Annual International Conference of the IEEE. 2011. IEEE. 
[12] Vance, B., et al., "Personal Health Records: Benefits And Barriers For Its Adoption". Insights to a Changing World Journal, 2014. 2014(4): pp. 48-67.

[13] Yamin, C. K., et al., "The digital divide in adoption and use of a personal health record". Archives of Internal Medicine, 2011. 171(6): pp. 568-574.

[14] Tétard, F. and M. Collan. "Lazy user theory: A dynamic model to understand user selection of products and services", in Proceedings of the 42nd Hawaii International Conference on System Sciences, IEEE, 2009.

[15] Kunene, K. N., K. Zysk, and MF. Diop. "Healthcare Consumers' Voluntary Adoption and Non- Adoption of Electronic Personal Health Records". in 27th Australasian Conference on Information Systems, University of Wollongong, Faculty of Business. Wollongong, NSW, Australia, 2016

[16] Ancker, J. S., et al., "Patient activation and use of an electronic patient portal". Informatics for Health and Social Care, 2015. 40(3): pp. 254-266.

[17] Abramson, E. L., et al., "Consumer Perspectives on Personal Health Records: A 4-Community Study". American Journal of Managed Care, 2014. 20(4): pp. 287-a298.

[18] Kavoussi, S., et al., "HIPAA for physicians in the information age". Connecticut Medicine, 2014. 78(7): pp. 425427.

[19] Patel, V. N., et al., "Low-income, ethnically diverse consumers' perspective on health information exchange and personal health records". Informatics for Health and Social Care, 2011. 36(4): pp. 233-252.

[20] Zapata, B. C., et al., "Mobile PHRs compliance with Android and iOS usability guidelines". Journal of Medical Systems, 2014. 38(8): pp. 81 .

[21] Taha, J., et al., "Factors affecting usage of a personal health record (PHR) to manage health". Psychology and Aging, 2013. 28(4): pp. 1124.

[22] Studeny, J. and A. Coustasse, "Personal Health Records: Is Rapid Adoption Hindering Interoperability?", Perspectives in Health Information Management, 2014. 11(Summer): pp. $1 \mathrm{e}-1 \mathrm{e}$

[23] Archer, N., et al., "Personal health records: a scoping review". Journal of the American Medical Informatics Association, 2011. 18(4): pp. 515-522.

[24] Turvey, C. L., et al., "Transfer of Information from Personal Health Records: A Survey of Veterans Using My Health eVet". Telemedicine and e-Health, 2012. 18(2): pp. 109-114.

[25] Young, R., et al., "“Willing but Unwilling": Attitudinal barriers to adoption of home-based health information technology among older adults". Health Informatics Journal, 2014. 20(2): pp. 127-135.

[26] Mitchell, B. and D. Begoray, "Electronic personal health records that promote self-management in chronic illness". OJIN: The Online Journal of Issues in Nursing, 2010. 15(3): pp. 1B-10B.

[27] Wagner, P. J., et al., "Personal health records and hypertension control: a randomized trial". Journal of the American Medical Informatics Association, 2012. 19(4): pp. 626-634.

[28] Saparova, D., "Motivating, influencing, and persuading patients through personal health records: a scoping review". Perspectives in Health Information Management, 2012: pp. 1.

[29] Alter, S., "Designing and engineering for emergence: A challenge for HCI practice and research", AIS Transactions on Human-Computer Interaction, 2010. 2(4): pp 127-140.

[30] Ajzen, I. and M. Fishbein, Belief, attitude, intention and behavior: An introduction to theory and research, AddisonWesley, Reading, MA, 1975.

[31] Fishbein, M. and I. Ajzen, "Belief, attitude, intention, and behavior: An introduction to theory and research". 1977.

[32] Davis, F. D., "Perceived usefulness, perceived ease of use, and user acceptance of information technology". MIS Quarterly, 1989: pp. 319-340.

[33] Bagozzi, R. P., F. D. Davis, and P. R. Warshaw, "Development and test of a theory of technological learning and usage", Human Relations, 1992. 45(7): pp. 659-686.

[34] Goodhue, D. L. and R. L. Thompson, "Task-technology fit and individual performance", MIS Quarterly, 1995: pp. 213-236.

[35] Goodhue, D. L., "Understanding user evaluations of information systems". Management Science, 1995. 41(12): pp. $1827-1844$

[36] Rogers, E.M., "Diffusion of innovations". Free Pres., New York, 2003.

[37] Vessey, I., "Cognitive fit: A theory-based analysis of the graphs versus tables literature". Decision Sciences, 1991. 22(2): pp. 219-240.

[38] Vessey, I. and D. Galletta, "Cognitive fit: An empirical study of information acquisition". Information Systems Research, 1991. 2(1): pp. 63-84.

[39] Ajzen, I., From intentions to actions: A theory of planned behavior, in Action Control, Springer, 1985, pp. 11-39.

[40] Madden, T. J ., P. S. Ellen, and I. Ajzen, "A comparison of the theory of planned behavior and the theory of reasoned 
action". Personality and social psychology Bulletin, 1992. 18(1): pp. 3-9.

[41] Benbasat, I. and H. Barki, "Quo vadis TAM?". Journal of the Association for Information Systems, 2007. 8(4): pp. 7

[42] Venkatesh, V., et al., "User acceptance of information technology: Toward a unified view". MIS quarterly, 2003: pp. 425-478.

[43] Sheppard, B. H., J. Hartwick, and P. R. Warshaw, "The theory of reasoned action: A meta-analysis of past research with recommendations for modifications and future research". Journal of consumer research, 1988. 15(3): pp. 325-343.

[44] Strauss, A. and J. Corbin, "Grounded theory methodology". Handbook of Qualitative Research, 1994. 17: pp. $273-85$.

[45] Strauss, A. and J. Corbin, Basics of qualitative research. Sage, Newbury Park, CA., 1990, Vol. 15.
[46] DiCicco-Bloom, B. and B. F. Crabtree, "The qualitative research interview". Medical Education, 2006. 40(4): pp. 314321.

[47] Strauss, A. and J. Corbin, Basics of qualitative research: Techniques and procedures for developing grounded theory, 2nd ed., Sage Publications, Thousand Oaks, California, 1998, 312.

[48] Lee, A.S. and R. L. Baskerville, "Generalizing generalizability in information systems research". Information Systems Research, 2003, 14(3): pp. 221-243.

[49] Schutz, A., Concept and theory formation in the social sciences, in Collected Papers I., Springer, 1962, pp. 48-66. 